\title{
A NOTE ON STOLARSKY, ARITHMETIC AND LOGARITHMIC MEANS
}

\section{VANIA MASCIONI}

Abstract. We present a way to study differences of some Stolarsky means as a way to discover new inequalities, or place known inequalities in a wider context. In particular, as an application we prove a very sharp upper bound for the difference between the arithmetic and the logarithmic means of two positive numbers.

Mathematics subject classification (2010): Primary: 26D20, Secondary: 26E60. Keywords and phrases: Stolarsky mean, arithmetic mean, logarithmic mean.

\section{REFERENCES}

[1] M. Alomari, M. Darus, S. S. Dragomir, New inequalities of Hermite-Hadamard type for functions whose second derivative's absolute values are quasi-convex, unpublished manuscript, online pre-print available at http://rgmia.org/v12(E).php (see article 17 on that page).

[2] B. C. CARlson, The logarithmic mean, Amer. Math. Monthly 79 (1972), 615-618.

[3] B. C. CARLSON, Special functions of applied mathematics, Academic Press, New York 1977.

[4] E. B. LeACH, M. C. Sholander, Extended mean values, Amer. Math. Monthly 85 (1978), 84-90.

[5] E. B. LeACH, M. C. Sholander, Extended mean values. II, J. Math. Anal. Appl. 92 (1983), $207-$ 223.

[6] E. Neumanm, Z. PÁles, On comparison of Stolarsky and Gini means, J. Math. Anal. Appl. 278 (2003), 274-284.

[7] Z. PÁLES, Inequalities for differences of powers, J. Math. Anal. Appl. 131 (1988), 271-281.

[8] C. E. M. PEARCE, J. PEČArić, V. Šimić, Stolarsky means and Hadamard's inequality, J. Math. Anal. Appl. 220 (1998), 99-109.

[9] K. B. Stolarsky, Generalizations of the logarithmic mean, Math. Mag. 48 (1975), 87-92.

[10] K. B. Stolarsky, The power and generalized logarithmic mean, Amer. Math. Monthly 87 (1980), 545-548. 